\title{
Experiences of BSN Students regarding Application of Nursing Theories at Clinical
}

\author{
Shireen Arif, Alia Nasir
}

\begin{abstract}
OBJECTIVE: To explore the experiences of BSN students regarding application of nursing theories at the clinical practice.

METHODOLOGY: Qualitative Phenomenology approach was used by using semi-structured questionnaire. Study was conducted at Ziauddin College of Nursing BSN Year IV Semester VIII students after completion of Nursing Theories course. Data was collected from four in-depth interviews from key informants and 3 Focus Groups having 6 members in each group. Data was collected till saturation occurs. Interviews were tape recorded and notes were also taken. Total 22 nursing students participated after signing consent form.

RESULTS: The result of the study revealed challenges at clinical site under that helpless, unavailability of subject expert instructor, lack of clinical faculty interest, delay in assignment submission and no long term application were emerged as the categories of the data.

CONCLUSION: The current study highlights the experiences of application of nursing theory while applying it at the clinical area.
\end{abstract}

KEYWORDS: Nursing theory, Application of nursing theory, Clinical.

This article may be cited as: Arif S, Nasir A. Experiences of BSN Students regarding Application of Nursing Theories at Clinical. J Liaquat Uni Med Health Sci. 2019;18(03):241-4. doi: 10.22442/jlumhs.191830635

\section{INTRODUCTION}

The framework of the nursing practices is thought to be the basis of nursingtheories ${ }^{1}$. Nursing theories not only provides the foundations for practices but also for the research, education, administration and professional development. It is responsible for the growth of nursing as a profession ${ }^{2}$. Nursing theories are the principles that reinforce practice and generate further knowledge regarding nursing profession ${ }^{3}$. There are many challenges in nursing practices one of them is least implementation of nursing theoretical concepts into clinical practice ${ }^{4}$. Nursing Theories are the part of nursing curriculum in Baccalaureate of Nursing program; however their application at the clinical area is lacking ${ }^{5-7}$. There is scarce literature available regarding application of nursing theories into nursing practice. However, a lack of agreement in the professional literature on nursing theory confuses nurses and has caused many to dismiss nursing theory as irrelevant to practice ${ }^{1}$. Any discipline is basis on its knowledge development.

Nursing discipline is also basis on its knowledge development through nursing theories. Lack of work on nursing theories and its elimination from practice and research will convert it from profession to the tasks needed by patients and their families ${ }^{1}$. The aim of the study is to explore the Experiences of BSN Students regarding Application of Nursing Theories at
Clinical. The literature available either provides the importance of nursing theories or it recommend that it should apply at the clinical area. The theories are the part of nursing curriculum and students are trying to apply them at the patient care area. No any literature identified in Pakistani context or in western context identifying the experiences of these nursing students while application at the clinical setting.

Researchers have documented clearly the gap between nursing theory and its practices. The main reason of this gap is lack of understanding of nursing theory's application at the clinical site. Instead of resolving the issue, nurses are ignoring its application. Due to this reason conundrum of gap between theory and practice is growing ${ }^{8,6}$. Idress S $2014^{7}$ highlighted the same issue that in this competitive and challenging era the main difficulty nurses are facing is the application of theoretical concepts into practice. Researcher further stated that knowledge of nursing theories and its application in to clinical practice helps to implement evidence based practices effectively. Evidenced based practices are significant in the health care environment. Researchers have endorsed the close relationship of nursing theories with the clinical practices based on evidenced based practices $^{5,10}$.

Ahtisham Y $2015^{4}$ indicated that the application of nursing theories into clinical practice varies from 
context to context. Ahtisham Y $2015^{4}$ also highlighted that there is dearth of knowledge in Pakistani context regarding nursing theory application into practice. Different researchers have implemented different theory in different context such as Idress S 2014 implemented theory of Florence Nightingale whereas, Ahtisham Y $2015^{4}$ implemented theory of Virginia Henderson. Saifan A $2015^{10}$ specified that since last three decades the main focus of nursing education is shifting from the hospitals toward the universities for the development of the profession. Due to this reason literature shows that there is a clear gap between what is taught in the class room and what the student nurses experience at the clinical area. Saifan A $2015^{10}$ conducted an exploratory qualitative research aimed to identify the reasons for the gap between theory and clinical practice. The finding of the study revealed that the lack of qualifications of the clinical instructors and lack of communication between Theory and Practice teachers.

The study concluded that nursing students has to face the challenges at the practice area due to the change in the theory and clinical teaching environments. Secondly, lack of communication between theory and clinical instructors increases the feelings of frustration and dissatisfaction among nursing students ${ }^{10}$. Kim HS $2012^{5} \& 2010^{11}$ emphasis the efforts made in health research for the incorporation of research evidence into healthcare decision-making.

Researchers further highlighted that nursing services and research can be improved through the use of nursing theory. Integrating theory into health services and research not only improves the research methodology, it further encourages strong collaboration among decision makers ${ }^{12}$.

Researchers are recognizing the importance of theory which demands for new projections in the practice of nursing services and research. Institutions and researchers should incorporate the use of theory for the improvement of nursing practices and betterment of nursing profession ${ }^{13}$.

\section{METHODOLOGY}

In this qualitative phenomenology study 22 participants were recruited from BSN IV semester VIII students of Ziauddin College of Nursing. Data was collected after approval from Ethics research committee, permission from the data collection site and informed consent signed by the participants. Only those students included through convenient sampling, which had $85 \%$ attendance and successfully completed the course of nursing theories. Three focused group interviews and four individual interviews conducted after successful completion of
18 weeks nursing theories course and its implication at the clinical area between the months of July and November 2018. The duration of each interview was 80 to 90 minutes approximately. The interview were recorded, data was transcribed and translated by the researcher. The data was read and reread to identify the codes, categories and themes.

\section{TABLE I: SEMI STRUCTURE QUESTIONNAIRE WITH FOLLOWING PROBING QUESTIONS WERE UTILIZED WHILE INTERVIEWING PARTICIPANTS}

- What do you understood about nursing theories?

- How these theories are beneficial to work at the clinical area or in patient care?

- What challenges you faced while applying these theories in patient care?

\section{RESULTS}

The data was analyzed through content analysis approach in which under the theme of challenges at the clinical was categorized in feeling helpless, delay in assignment submission, un availability of subject clinical instructor, lack of clinical faculty interest, no long term application were identified.

\section{TABLE II: EXPERIENCES OF BSN STUDENTS REGARDING APPLICATION OF NURSING THEORY AT CLINICAL}

\begin{tabular}{|c|ll|}
\hline $\begin{array}{c}\text { Challenges } \\
\text { at Clinical }\end{array}$ & $\bullet$ & Feeling Helpless \\
& Unavailability of subject expert \\
& $\begin{array}{l}\text { instructor } \\
\text { - }\end{array}$ \\
& Lack of clinical faculty interest \\
& Delay in assignment submission \\
\hline
\end{tabular}

\section{Challenges at Clinical}

The participants of the study stated that they felt helpless at the clinical because of no one to guide that how to select patient and how to apply nursing theories at the clinical area. Participant $A$ verbalized, "On first step of selecting patient to implement theory, I was lost and felt like helpless. I was confused that how I should select a patient and implement theory". Participant B shared, "On clinical while applying theory at the patient I was lost and helpless, as there was no one to help out. There was no one to help me at the clinical".

Participants of the study also emphasis that due to unavailability of the subject expert instructor at clinical side students often face difficulty in application of the nursing theories. Participant D verbalized, "In class everything goes good, but on clinical I didn't find anyone to whom I could take guidance". Participant G stated, "Our course expert faculty do not come on clinical, to guide us. If she is there we could ask for 
assistance". Participant C verbalized, "I did not ask staff nurse and clinical teacher because they are not subject experts".

Participants of the study further stated that the other main challenge they faced while application of nursing theories at the clinical area was the lack of interest of the clinical instructor in the application of nursing theories. Participant G expressed that, "Several times I had asked clinical teachers but she was not known about the theory and its concepts. So now I do not ask any one again". Participant E said, "Clinical instructors do not show their interest in nursing theories and its implementations on patient, might be they are not clear in their concepts".

The other category emerged was the delay in the assignment submission. As it was the requirement of the course that student has to submit the reflection of their work after implementation of the theory at clinical setting. The student faced difficulty in submission of their assignment on due time due to no proper guidance of implementation at the clinical site. Participant $\mathrm{H}$ verbalized, "Whenever I asked any clinical instructor regarding any concept or implantation of some concepts of assigned theory at patient, they twist topic in something else and our queries remain same. This cause delay in submitting our clinical assignments too".

The last challenge verbalized by the participants of the study was the lack of policy due to which nursing theories could be utilized as long term in the clinical area. Participant $\mathrm{K}$ expressed their experience in a way that, "At the clinical site there should be some policy or compulsory documents that made in the way that we could implement these theories at the clinical in long run". Participant M verbalized, "When I will become the staff nurse I might have forgotten all theories except theory of Florence nightingale because of her big picture at every nursing counter. If there are pictures of other nursing theorists with their work, I might recognize them too".

\section{DISCUSSION}

The result of the study clearly state that students faced challenges at the clinical area for the application of nursing theories. Nursing education is not completed without its execution of practice at the clinical site. Although students understood nursing theories course in the class but the process of understanding nursing theories is in complete without execution at the clinical site. The data analysis of the current study identified that student's challenges at the clinical area includes feeling helpless due to the unavailability of the subject expert instructor at the clinical site. The study findings could not be compared with other findings due to the limitation of researches done for the same aim. Study conducted by the Saifan A $2015^{10}$ identified that poor communication between instructors and lack of support due to their less interest in nursing theories tends to decrease student learning and implementation of theories at the clinical area.

Due to this students felt dissatisfaction tends to increase their frustration at the clinical area. Furthermore, the clinical faculty and the senior nursing staff found to have lack of interest in the application of theories. Moreover, nursing students also stated that due to these reasons they felt helpless and their assignments submissions delayed. Gonzalez MA $2014^{14}$ supports the findings of the current study and stated that staff nurses and nurse educators are less equipped to perform the required role of the instructor, such as educator, researcher.

The researcher also emphasizes that there should be continuous relationship among teachers teaching theory and practices. The study conducted by Tiwaken SU $2015^{9}$ supported the findings that practice of theory at clinical side will helps the nursing students to gain more confidence at the clinical side in providing accurate care and skills. Clinical instructors and supervisors need to design strategies in new innovative ways to motivate nursing students to implicate these nursing theories at the clinical area ${ }^{15}$. Study conducted by Mohammadi E $2015^{16}$ identified that most workable need among nurses was the implementation of nursing theory at the clinical area. Researchers recommended that there should be in service sessions for modifying nurse's attitude and for encouraging implementation of nursing theories.

\section{CONCLUSION}

The current study highlights the importance of application of nursing theory and experiences of nursing students while applying it at the clinical area. Students shared that they felt helpless while applying nursing theory when there is unavailability of subject expert instructor at the clinical area. Furthermore, the lack of interest of clinical faculty in nursing theories led them towards more confusion due to which their submission of assignment is delayed.

Students further stated that there is no plan available for long term application of nursing theories at clinical placement. The hidden meanings from the data stated inferred that students find nursing theories beneficial but they are implementing it for the sake of assignment submission, as it is compulsory requirement of nursing theory course to pass. On the other hand there is no long term plan available for sustainability.

Ethical permission: Ziauddin University Institutional IRB Permission letter Reference No. 01504SANUR 
Dated: 18-05-2018.

Conflict of Interest: There is no conflict of interest

Funding: All expenses were managed by the authors of this study only.

\section{REFERENCES}

1. Colley S. Nursing theory: its importance to practice. Nurs Stand. 2003; 17 (46); 33-37.

2. Karnick PM. A Case for Nursing Theory in Practice. Nurs Sci Q. 2014; 27(2): 117. doi: $10.1177 / 0894318414522711$.

3. Meleis A. Theoretical nursing development and progress. 5th ed. Philadelphia: Wolters Kluwer Lippincott Williams \& Wilkins; 2012.

4. Ahtisham $Y$, Jacoline $S$. Integrating Nursing Theory and Process into Practice; Virginia's Henderson Need Theory. Int J Caring Sci. 2015; 8 (2); 443- 50.

5. Kim HS. The Role of Theory in Clinical Nursing Practice. Klinisk Sygepleje 2012; 26(2): 16-29.

6. Tonges M, Ray J. Translating caring theory in to practice: the Carolina Care Model. J Nurs Adm. 2011; 41(9): 374-81. doi:10.1097/ NNA.0b013e31822 32c.

7. Idress S. Clinical application of nursing theory in to practice. i-Manager's J Nurs. 2014; 4(1): 23-27. doi:10.26634/jnur.4.1.2628.

8. Hussein MT, Ousji J. Bridging the theory practice dichotomy in nursing: the role of nurse educators. J Nurs Edu Pract. 2016; 7(3): 20-25. doi:10.5430 / jnep.v7n3p20

9. Tiwaken SU, Caranto LC, David JT. The Real World: Lived Experiences of Student Nurses during Clinical Practice. Int J Nurs Sci. 2015; 5(2): 66-75 doi: 10.5923/j.nursing.20150502.05.

10. Saifan A, AbuRuz M, Masa'deh R. Theory practice gaps in nursing education: a qualitative perspective. J Soc Sci. 2015; 11(1): 20.29 . doi:10.3844/jssp.2015. 20.29

11. Kim HS. The nature of theoretical thinking in nursing. 3rd ed. New York: Springer Publishing; 2010.

12. Brazil K, Ozer E, Cloutier M, Levine R, Stryer D. From theory to practice: improving the impact of health services research. BMC Health Serv Res. 2005; 5:1. doi:10.1186/1472-6963-5-1.

13. Brasell-Brian R, Vallance E. Clinical practice/ education exchange: Bridging the theory practice gap. Nurs Prax N Z; 2002; 18(1): 17-26.

14. Gonzalez MA, Badia MC, Font CM. The identity of the nursing academic: between education and research. Text Context Nurs. 2014; 23(2): 241-9. doi: 10.1590/0104-07072014001640013.

15. Arora S. Integration of Nursing Theories in Practice. Int J Nurs Sci Pract Res. 2015; 1(1): 8-12.

16. Mohammadi E, Abbasi K, Saadati M. Barriers to implementation of nursing theories in clinical practice from the perspective of nurses. Iran J Nurs Res. 2015; 10(1): 13-24.

AUTHOR AFFILIATION:
Shireen Arif (Corresponding Author)
Assistant Professor
Ziauddin College of Nursing
Ziauddin University Karachi, Sindh-Pakistan.
Email: shireen.arif29@gmail.com
Alia Nasir
Associate Professor
Ziauddin College of Nursing
Ziauddin University Karachi, Sindh-Pakistan.

